\title{
Fenomenología del cuerpo como expresión e interpretación
}

\author{
$\mathrm{M}^{\mathrm{a}}$ LUZ PINTOS PEÑARANDA \\ Universidad de Santiago de Compostela
}

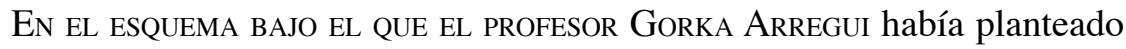
estas Jornadas de reflexión sobre el cuerpo mencionaba la convergencia de diferentes orientaciones del pensamiento occidental a la hora de considerar el cuerpo como un texto, y entre estas orientaciones se incluía a la Fenomenología. Yo intentaré aquí seguir fielmente el encargo de nuestro querido amigo y reflexionar, desde un enfoque fenomenológico, sobre el cuerpo como texto.

Como cuestión preliminar, hemos de plantearnos lo que es un texto en su sentido más elemental: es todo él expresión y lo que en él está expresado es para ser leído por alguien, es decir, que el texto todo es para ser interpretado y comprendido. Normalmente, cuando hablamos de un "texto" es para referirnos a un texto que, bien sea en soporte papel o bien en el moderno soporte electrónico, contiene signos gráficos, de escritura gráfica, es decir, letras que simbolizan sonidos y palabras que, a su vez, simbolizan alguna cosa de nuestro mundo. Por tanto, cuando hablamos de un "texto" es para referimos a un texto con símbolos, siendo los símbolos representaciones de ese sentido con el que previamente se ha envuelto lo que se quiere representar. Y es importante hacer notar que los símbolos son creados de un modo premeditado, artificial y convencional, por nosotros, los humanos de determinada cultura; es decir, los símbolos siempre son fruto de una invención o creación y, desde el momento en que se inventan, aquellos que por lo que sea tienen éxito, llegarán a todos los miembros de una cultura por transmisión cultural y nunca genética-lo cual es una diferencia esencial con respecto a las señales o signos naturales ${ }^{1}$ ya que

1 No debemos confundir lo que llamamos "símbolo" con lo que llamamos "señales" o "signos" naturales indicativos; por ejemplo, para una madre el lloro de su bebé actúa como "señal" (natural) para que acuda a donde él está. En ella hay un mecanismo biológico que la impulsa a ir hacia su bebé cuando oye su llanto; no tiene que aprender qué significa esa señal. Otro ejemplo: los nubarrones son para nosotros señal de que va a llover o de que se avecina 
los símbolos únicamente existen si son inventados como tal, si son producto de nuestra creación cultural. Y -algo especialmente importante para la argumentación que desenvolveré- su invento requiere la intervención consciente del intelecto ${ }^{2}$.

La tesis que aquí voy a exponer -y que ya quiero anticipar ahora- consta de dos partes:

a) En primer lugar, el primer texto con el que contamos, es el cuerpo, el cuerpo vivo y animal, nuestra corporalidad viviente; ella es el lugar natural de la expresión y de la interpretación y comprensión, el lugar originario de éstas. Por tanto, la expresión e interpretación del cuerpo vivo ya están dadas para nosotros de forma natural e inmediata sin que tengamos que buscarlas, aprenderlas o producirlas adrede e intelectualmente.

Sin embargo, como veremos, al afirmar así no vamos a tomar este primer texto como un texto con símbolos, como un texto simbólico, entendiendo por ello, un texto cultural. En principio, vamos aquí a referirnos a la corporalidad a otro nivel; $y$ en este nivel se hace evidente que este texto de la corporalidad es tan especial que, para él lograr expresar algo y para que los que están ante él sean capaces de interpretarlo y comprender lo que expresa, no es necesario el uso del intelecto racional voluntario. Para la expresión y la interpretación y comprensión de este texto tan especial no se necesita esfuerzo intelectual, es decir, no se necesita este esfuerzo, y no se necesita siquiera aprendizaje cultural, ni para expresarse inequívocamente a través de él ni para saber interpretar y comprender correctamente lo que él expresa.

b) En segundo lugar, aunque la expresión e interpretación de la corporalidad humana en su modo primigenio de darse no son racional-simbó-

una tormenta. En este caso, no hay que inventar nada, sino que tan sólo necesitamos tener una o unas pocas experiencias y fijarnos en que después de que aparecen los nubarrones llueve para enlazar esa señal natural con la lluvia.

2 Por ejemplo, nuestros antepasados inventaron hace tiempo este tipo de escritura que hoy usamos y cada uno de los nuevos individuos que vamos naciendo o viniendo a nuestra cultura somos instruídos (racionalmente) en el sonido que simboliza cada letra y en el sentido o sentidos que van ligados a cada una de las palabras de nuestra lengua hablada y escrita. Y todos los que estamos en esta sala hemos vivido la experiencia de tener que esforzarnos (racional o intelectualmente) hasta completar este aprendizaje cultural de la escritura y de la lectura. Es decir, que nos hemos pasado varios años aprendiendo en el colegio hasta conseguir leer e interpretar sin dificultad lo que expresa simbólicamente un texto escrito y hasta poder poner por medio de estos símbolos que son las letras lo que queremos expresar en papel. 
licas, por supuesto que, de un modo u otro, como es un hecho que el vivir del individuo se lleva a cabo dentro de un grupo cultural, muy pronto esta expresión e interpretación se convertirán también-digo "también" y no sólo- en culturales, es decir, en simbólicas, con intervención de nuestro raciocinio. Y aquí nos estaremos moviendo en otro nivel diferente al anterior. Realmente, en los humanos, esto comienza ya con el nacimiento de cada nueva criatura y hace que la expresión e interpretación y comprensión del cuerpo siendo "naturales" sean, a la vez, e inextricablemente, "culturales" desde el inicio de cada nueva vida, aunque aquí, analíticamente -y sólo analíticamente-, intentemos desglosar el cuerpo como texto "natural", por un lado, como texto "cultural", por otro lado.

Vamos a hablar, pues, a la manera fenomenológica -la cual es puramente descriptiva- de la corporalidad como texto, como lugar de expresión y de interpretación y comprensión. Y ya inmediatamente nos damos cuenta de que éste no es un lugar cualquiera, un lugar entre otros muchos, sino la cuna de la expresión y de la interpretación. En efecto, hablar de la corporalidad nos sitúa en un nivel pre-racional de expresión y de interpretación y, como tal, en un nivel que es anterior a, y más básico que, el nivel racional, cultural. Decir esto no significa que aquí estemos defendiendo la idea de que el nivel de la corporalidad humana del que decimos que es "anterior" sea anterior cronológicamente hablando. No; cronológicamente hablando, tanto el nivel natural de la corporalidad como el nivel cultural están presentes en el neonato desde el inicio de su vida en el seno de un grupo o, simplemente, en el seno de la convivencia con su madre. Más bien utilizamos el adjetivo "anterior" en el sentido de que el neonato ya viene dotado genéticamente de este nivel de expresión y de interpretación y comprensión y que, espontáneamente, "naturalmente", podrá él ejercer una expresión que de modo "natural" será perfectamente comprendida por los que le rodean sin que medie para ello ninguna intervención de aprendizaje "intelectual" y "cultural". A la vez, desde el mismo momento del parto, los otros que le rodean ejercerán sobre el neonato una influencia que habrá de ir imprimiendo en él, convencionalmente, un modo de expresarse "simbólico-cultural" que irá aprendiendo y cuya interpretación y comprensión por los otros sólo será posible gracias a una aprehensión intelectual y simbólico-cultural también aprendida. Sin embargo, normalmente nos centramos en este segundo nivel racional y cultural de la corporalidad e incluso partimos de él como si sólo fuera éste el nivel en el que desenvolvemos nuestras vidas. Y con frecuencia, cuando hacemos así, ya es- 
tamos arrastrando ideas prejuiciosas, es decir, ese tipo de ideas que asumimos sin más porque son las que están vigentes en nuestra cultura y a las que estamos como atados de forma natural e inconsciente, sin posibilidad de distanciarnos de ellas de forma crítica. El método fenomenológico consiste precisamente en intentar tomar esta distancia y en refundar nuestras ideas de un modo consciente; de un modo que va a partir de lo que hay, es decir, de la experiencia vivida en la que todos y cada uno estamos ya, para limitarse a describirla.

Vamos, pues, a partir de un hecho elemental para hacer esta descripción fenomenológica del cuerpo como texto o, lo que es lo mismo, vamos a hacer una búsqueda de la esencia de estos actos del sujeto que son la expresión y la interpretación: "toda existencia es un estar-corporalmente-en-el-mundo"”. Existir, estar en el mundo, sólo puede ser gracias al cuerpo. Pero, ¿de que cuerpo se trata? No es que haya dos tipos de cuerpos en cada uno, o cada una, de nosotros. En nuestro vivir cotidiano, actuamos como una existencia una e indivisa. Sin embargo, analíticamente, sí que podemos contemplar nuestro cuerpo desde ángulos diferentes. Y entonces, analíticamente, diremos: una cosa es nuestro cuerpo físico y otra nuestro cuerpo fenoménico; es decir, una cosa es el cuerpo objetivo y otra es el cuerpo vivido, el mío propio, el vivido por mí, el que yo vivo desde mí; una cosa es el extracuerpo y otra es el intracuerpo, como diría Ortega ${ }^{4}$. ¿En cuál de estos dos sentidos estamos tomando, pues, al cuerpo cuando afirmamos que existir consiste en estar en el mundo y que esto únicamente es posible gracias al cuerpo? Vamos a complicar un poco más la pregunta pasando a plantear otra que, aunque a simple vista no lo parezca, es la misma: ¿En dónde nace, para todo existente, la posibilidad de expresarse $y$ de interpretar: en su cuerpo físico o en su cuerpo vivido? Evidentemente, al plantear así esta pregunta de hecho estamos equiparando ahora el ser un existente, un ser en el mundo, con el ser un ser de expresión y de interpretación, con el ya-estar-en-la-expresión-y-en-la-interpretación comprensora. La posibilidad -inesquivable- de estar expresándose e interpretando constantemente, ¿nace en el cuerpo físico? O, ¿nace más bien en el cuerpo vivido, en el intracuerpo (en el Leib, para Husserl)? Pero, ¿es que realmente, cuando nos estamos refiriendo a los humanos, podemos pensar tan sólo en el cuerpo físico, ignorando el vivido?, o, al revés, ¿podemos pensar tan sólo en el cuerpo vivido ignorando el físico? Muy confundidos estaríamos si nos quedamos con uno u otro, privilegiando a uno y desestimando la necesidad e importancia del otro. Porque es verdad

3 Es ésta una tesis absolutamente nuclear y siempre, pues, punto de partida de la interpretación fenomenológica. Cito aquí a Frederik Buytendijk (cfr. su libro La mujer, Madrid, Revista de Occidente, 1970, p. 16) pero podríamos citar a cualquier otro fenomenólogo.

4 Cfr. José Ortega y Gasset "Vitalidad, alma, espíritu", en O. C., Madrid, Revista de Occidente, 1946, vol. II., passim. 
que, como decíamos, analíticamente, cuando estamos moviéndonos en un nivel reflexivo para así captar de modo cognoscitivo lo que de hecho ya somos, nos expresamos de este modo: tenemos lo que es la corporalidad externa, material, física, y tenemos el "cómo le va a uno"-que diría Heidegger-, el cómo uno vive la vida directamente desde sí mismo. Sin embargo, esta división que forzamos a un nivel reflexivo no se da en la vida concreta del existente humano. Una vida biológica sin ser hecha desde el yo del individuo no sería humana. Y, viceversa: es imposible que uno pueda orientar la vida desde sí mismo si no cuenta ya con una vida real, es decir, con una vida materializada, corporalizada físicamente. No puede darse, pues, en los humanos, intracuerpo sin un extracuerpo con las características humanas, ni extracuerpo que se exprese al modo humano sin su intracuerpo. En definitiva, y para usar una fórmula rápida que habremos de tomar en este doble sentido del que estoy hablando, somos seres psico-somáticos.

"Toda existencia es un estar-corporalmente-en-el-mundo", decíamos antes. Y ahora, esta fórmula la hemos aclarado un poco más: "Toda existencia es un estar psico-somáticamente en el mundo". Pero todavía hemos de ver algunas de las implicaciones que esto entraña. Por ejemplo, ésta: "Somos seres psicosomáticos que existen en el mundo en cuanto existentes mundanos situadosentre-otros-existentes-mundanos"5. Y esto es así desde nuestros orígenes como homo sapiens y, más para atrás, desde nuestros orígenes como homo, y más para atrás, por lo menos desde nuestros orígenes como mamíferos primates. ¡Desde la época más remota de nuestros ancestros, siempre hemos sido mamíferos que viven en grupo! Y pertenecer al orden de los mamíferos, y, además, de los mamíferos que viven en sociedad, en convivencia con otros congéneres, explica algunas de nuestras características que heredamos y que conservamos desde esos ancestrales orígenes y que, como veremos, atañen directamente al tema que aquí nos ocupa.

Todo individuo humano es primeramente un ser vivo-animal-corpóreoperceptivo-práxico (es decir, activo, actuando, en actividad práxica); y, como tal, se halla en permanente-experiencia-de contacto (corpóreo-perceptivo-práxico)-con su mundo entorno, es decir, con lo otro y los otros, ya sean animales no humanos o congéneres. De hecho, para Husserl, para la fenomenología, el sujeto humano y el mundo en el que está inmerso están tan estrechamente vinculados entre sí que no se comprenden el uno sin el otro. Y la interrelación es continua y sin que pueda no darse. Como aquí no tenemos mucho tiempo, me ceñiré a la interrelación entre cada sujeto humano y los otros humanos que con él comparten su mundo.

5 Aron Gurwitsch El campo de la conciencia. Un análisis fenomenológico, Madrid, Alianza Editorial, 1979, p. 489. Guiones entre las palabras míos. 
Esta interrelación no es algo que pueda darse o no darse, indiferentemente, sino que resulta inesquivable e imprescindible. Desde que llega a este mundo, toda nueva criatura nacida de mujer necesita biológicamente de sus congéneres. Podemos, incluso decir, que nacemos siendo esencialmente necesitantes de los demás. Pero ya no sólo porque, para nuestra sobrevivencia, precisamos nutrición y amparo y porque quienes mejor nos pueden aportar esto son nuestros congéneres, sino también porque, para llegar a constituirnos como humanos y a adquirir los rasgos primordiales que nos son propios de nuestra especie, es totalmente imprescindible el contacto con los congéneres y que de ellos aprendamos estos rasgos. Sin mediar este contacto y este aprendizaje (por tanto, cultural) sobre cada nuevo nacido de mujer, ninguno de nosotros conseguiríamos caminar bípedamente, ni hacernos con un lenguaje simbólico, ni razonar simbólicamente ni, por supuesto, manejar nuestras manos de modo que con ellas seamos capaces de construir instrumentos para el manejo y aprovechamiento inteligente de nuestro entorno. Por consiguiente, debido a nacer tan indefensos y necesitantes, estamos naturalmente obligados a mantener una íntima y continua relación de contacto cultural con los otros congéneres; incluso para alcanzar, cada uno y cada una de nosotros, su carácter de animal "humano". De este modo, es un hecho que el encuentro intersubjetivo nos interpenetra desde los primeros momentos de nuestra existencia y que, así, la subjetividad es - desde su misma raíz y en cada uno de los momentos de su vida- intersubjetividad.

La subjetividad sólo es lo que es en la intersubjetividad ${ }^{6}$, es decir, gracias al contacto con los otros. Por tanto, ya no es sólo que necesitamos la coexistencia, el contacto intersubjetivo con los otros congéneres, sino que es un hecho que cada uno y cada una de nosotros, humanos, ya estamos permanentemente en la experiencia intersubjetiva desde nuestro nacimiento. Y esto supone que unos y otros continuamente nos estamos encontrando entre nosotros corpóreamente, es decir, perceptivamente y, en un encuentro en el que los unos estamos actuando, teniendo algún tipo de comportamiento, ante los otros y con los otros.

Desde que somos nacidos a este mundo intersubjetivo ninguno de nosotros puede ya sustraerse a esta continua experiencia del encuentro "cara a cara" con el otro. Un encuentro psicosomático en el que los otros y yo, yo y los otros, nos valemos de unas vías o medios de comunicación que ya vienen insertos en nuestra propia biología, a modo de posibilidades o capacidades congénitas: el tacto, la voz, la vista, y los gestos y movimientos todos del cuerpo. Son también medios de comunicación entre nosotros el gusto y el olfato ${ }^{7}$. Esto significa que

6 Cfr. Edmund Husserl La crisis de las ciencias europeas y la fenomenología trascendental, Barcelona, Crítica, 1990, § 50, p. 181.

7 Puede parecer que casi no usamos el gusto para interrelacionarnos en nuestras modernas civilizaciones actuales, pero sin duda que sí. Por ejemplo, todos sabemos cuánto puede gustar el 
el cuerpo humano viene preparado con las vías perceptivas básicas para llevar a cabo la interrelación con los congéneres a un nivel básico. Genéticamente, cada uno de nosotros y nosotras venimos al mundo dotados con estos elementales medios para conseguir contactar con el otro y expresarnos a este nivel tan básico del tacto, de la voz, de la vista, de los gestos, posición y movimiento corporales, del gusto y del olfato. Y, cada uno de nosotros y nosotras venimos al mundo dotados genéticamente de estos mismos elementales medios para percibir a los demás, en una percepción que, como veremos, no es meramente física, ejercida desde nuestro cuerpo físico o extracuerpo, sino que también es una percepción vivida, es decir, interpretada.

Antes decíamos que si nuestra biología trae consigo la necesidad de coexistir y de interrelacionarnos con los congéneres desde el principio de nuestras existencias es evidente que nuestra naturaleza biológica ha de venir preparada para poder llevar a cabo con cierto éxito esta coexistencia e interrelación social y, finalmente, la integración en una comunidad humana. Pero los medios a los que me acabo de referir no son todos los medios con los que biológicamente ya contamos para esta convivencia de los unos-con-los-otros. No; hay más medios. Al nacer traemos con nosotros unos mecanismos que son también la base biológica posibilitante de esta convivencia e intercomunicación entre humanos. De ahí que, si aquí estamos hablando de la corporalidad humana como el primer texto natural, esto es porque en él funcionan de forma espontánea estos mecanismos biológicos que ya vienen en nuestra dotación genética de animales mamíferos y porque, en cuento tal, son mecanismos enteramente naturales. En alguna otra ocasión me he referido a ellos como mecanismos de tres tipos: la empatía, las emociones (las cuales siempre son evaluadoras de la realidad) y la tolerancia ${ }^{8}$. Por la premura del tiempo y por ceñirme lo más

sabor de un beso de boca, o cuánto puede desagradar, dependiendo de cómo sepa, de cómo sea su sabor. Y si se da el segundo caso, de ello quizás dependa que la pareja no funcione. Y el olfato siempre ha tenido importancia entre los humanos, tanto entre los de épocas remotas como los de todas las épocas "esto lo saben bien los de la industria de perfumes y demás potingues para untar sobre el cuerpo; es verdad que ahora, en nuestras sociedades occidentales, hay más higiene, a veces una exagerada higiene, y que estamos obsesionados por eliminar todo olor corporal que pueda llegar al olfato de los vecinos; nuestra pituitaria apenas puede alterarse hoy con los olores naturales del otro hasta el punto de que, por ejemplo, le exciten y le muevan a un acercamiento sexual; esto hoy no pasa mucho porque sencillamente eliminamos esta posibilidad con tanto lavarnos; sin embargo, los perfumes que nos venden pueden llevar estratégicamente incorporadas sustancias que producen este efecto que tendría lugar de modo natural si no hubiéramos eliminado nuestro olor. Y lo que sí no ha dejado de suceder es que cuando uno suda en exceso y llega a oler mal, automáticamente los otros se van alejando.

8 Estos son tres mecanismos que interactúan entre sí hasta tal punto que, quizás, toda división que queramos hacer entre ellos no pueda tomarse más que como un intento de des- 
posible al tema sobre el que nos hemos propuesto reflexionar aquí me voy a referir tan sólo al primero de ellos: a la empatía. Este mecanismo conformará, pues, el núcleo de mi argumentación.

La empatía (Einfiuhlung) es la capacidad de captar al otro de modo intuitivo y emotivo. Es decir, no se trata aquí de una captación racional. Y ha habido siempre mucha confusión respecto a esto. La empatía no está ligada a un proceso cognoscitivo. La empatía no es un comprender "racionalmente" lo que el otro siente ni un hacerse uno una especie de "representación mental" de lo que el otro siente. Si así fuera y la comprensión empática estuviera vinculada a un proceso cognoscitivo de este tipo, entonces, una de las absurdas consecuencias que se derivarían de esto es que los bebés humanos, como nacen sin su capacidad de raciocinio desarrollada, no contarían con la empatía hasta que ellos alcanzaran un cierto grado de desarrollo; para lo cual habría que esperar a la edad de unos tres años. Sin embargo, es un hecho probado que los humanos contamos con la empatía desde el inicio de nuestra vida. Porque es justamente en nuestros primeros meses de vida y en los dos o tres primeros años cuando más necesitados estamos los humanos de ella. Podemos decirlo así: cuanto menos maduro está nuestro raciocinio, con más fuerza opera en nosotros, de forma espontánea, es decir, sin premeditación, sin intervención racional, este mecanismo de interrelación natural $-\mathrm{y}$, por tanto, de sobrevivencia- que es la empatía?.

Y, ¿por qué contamos con este mecanismo de la empatía? ¿cuál es su sentido? Y, ¿para qué habría de necesitar la empatía un recién nacido? ¿Cuál es la función que ésta desempeña en un sujeto humano desde el inicio de su vivir? ¿Podría, acaso, el bebé carecer de empatía dentro de lo que es su vida en esa etapa? Son todas buenas preguntas. Y hay que buscarles respuesta. Una respuesta yendo -para limitarnos a hacer una descripción-a cómo es la vida del bebé y cómo es la relación que él mantiene con los que le rodean y, viceversa, a cómo es la relación que los que le rodean mantienen con él. El hecho es que nuestra indefensión y estado necesitante en los primeros estadios de vida origina la necesidad de ser ayudados por los otros y para ello - jcosa absolutamente

cripción meramente "analítica". Los tres están imbricados entre sí tan estrechamente que, en la práctica, son uno y el mismo mecanismo, y se hacen difícilmente discernibles. He expuesto esta interpretación en "¿Dónde nace el sentido de la tolerancia y cómo valernos de él racionalmente? Aportación desde la fenomenología", Ponencia en el XV Congreso InTERAMERICANO DE FiLOSOFía / II Congreso Iberoamericano de Filosofía: “Tolerancia”, Lima (Perú), 12-16 de enero de 2004. Actualmente está en prensa en Rosemary Rizo-Patrón / Cecilia Monteagudo (eds.) Interpretando la experiencia de la Tolerancia, Lima.

9 Aunque también es cierto que durante el resto de la vida del sujeto nunca deja de funcionar. Precisaré esto más adelante. 
importante!- la necesidad de "entendernos con" ellos y de interaccionar con ellos con éxito desde mucho antes de estar preparados para comprender de modo cognoscitivo esta relación y para buscarla de un modo premeditado, consciente, racional, cultural.

Vamos a poner varios ejemplos para ver esto de un modo gráfico. Pero antes parémonos en la definición que hemos hecho de la empatía y en cómo esta definición enlaza con el tema que da título a esta conferencia: la empatía - decíamos- es la capacidad de captar al otro de modo intuitivo y emotivo, sintiendo lo que él siente, poniéndonos en su propia piel. La empatía parece, pues, que es cosa de dos sujetos; o de cómo mínimo dos sujetos: un "yo" y un "tú". Es decir, uno que le está expresando algo al otro y el otro, que está ante él, percibiéndolo en persona (por alguno de sus sentidos; no necesariamente o sólo por el de la vista), y que consigue comprenderle empáticamente, o sea, que consigue interpretar y comprender de forma rápida, inmediata, de modo intuitivo y natural, eso que está expresando, y que lo está expresando también de un modo natural. Y cuando digo "natural", inmediato, intuitivo, todo esto significa, en definitiva, de un modo "no racional", sino previo a un carácter racional y cultural. Cuando el que expresa algo lo expresa de modo natural (es decir, no cultural; únicamente con su cuerpo psicosomático) y cuando el que está ahí percibiéndole, lo percibe en directo ${ }^{10}$, gracias también a su cuerpo psicosomático, entonces es cuando se pone en funcionamiento este mecanismo natural y espontáneo que es la empatía y que opera desde el cuerpo (y no desde la razón).

Las que somos madres sabemos muy bien lo que es experimentar en nuestra propia carne lo que está experimentando nuestro bebé en la suya. Cuando mi bebé de quince días llora con un determinado tipo de lloro, yo comprendo, in-

10 La empatía, como mecanismo biológico que es, sólo se activa en el encuentro "cara a cara" directo en toda vida animal. Pero, a diferencia de los otros animales, en los humanos puede entrar en funcionamiento sin haber un cara a cara directo, sino sólo indirecto. Esto ocurre porque los humanos contamos con el "además" de la imaginación racional. Nosotros, valiéndonos de la imaginación, podemos "imaginar" cómo el otro se está sintiendo aunque no lo tengamos personalmente delante. Dos ejemplos. A) Estoy leyendo una novela. El protagonista está esperando a su novia con pasión de enamorado y, de repente, alguien le comunica la noticia de que el tren en el que venía hacia él ha tenido un accidente y que no hay sobrevivientes. B) Un amigo me telefonea para decirme que una amiga común ha conseguido el puesto de trabajo por el que estuvo luchando durante diez últimos años como principal objetivo de su vida. En ambos casos, yo no tengo en percepción directa ni al enamorado ni a la nueva trabajadora, pero yo puedo imaginar empáticamente el estado de total desconsuelo, en el primer caso, y de desbordante alegría, en el segundo caso, de esas dos personas, y ponerme a llorar de pena en el primero y a brincar de alegría en el segundo. La imaginación actúa "como si" yo estuviera percibiendo el estado de esas personas directamente, aunque de hecho sólo tenga noticia de su estado indirectamente. 
mediatamente, que algo no marcha bien en él y que él está incómodo por algún motivo o que le duele algo. Por supuesto que el sonido del lloro ha actuado para mí como una señal natural a modo de llamada o reclamo para que yo acuda a ver qué le pasa -ies el único modo que tiene en esos momentos el bebé para llamar mi atención, ya que todavía no me podría llamar diciendo: "mamá, ven aquí que me encuentro mal y te necesito urgentemente". Sus neuronas todavía no están mielinizadas; no puede razonar buscando el modo de conseguir mi presencia, ni todavía ha sido inculturado en la lengua de su entorno y, por tanto, no sabría llamarme con palabras. ¿Es que, entonces, no tiene ningún recurso? Sí, justamente los recursos que ya vienen en su naturaleza biológica de ser vivo animal. Tiene aquí la voz y los gestos y el movimiento de su cuerpo, en este caso concreto que estoy poniendo como ejemplo. El bebé se encuentra mal. Su temperatura ha subido. Necesita a su mamá. Para conseguir que yo vaya, llora fuertemente con un lloro cómo de dolor, insistente. Y cuando yo acudo hasta su cuna atraída por este lloro, al verlo agitando sus brazos y sus piernas, con su carita toda roja, sudando mucho, siento que algo va mal en él. Cuando mi bebé está mal, gracias a todos estos medios naturales que él utiliza para expresar que está mal, mi empatía se pone en funcionamiento inmediatamente y él consigue una relación conmigo, es decir, con un congénere, exitosa; exitosa en el sentido de que finalmente yo le ayudo: telefonearé al médico, marcharé con él a urgencias, o haré cualquier otra cosa apropiada. Alguien podría objetar que, en este ejemplo, no es en el bebé en el que está operando la empatía. Y esto es cierto, pero sólo desde un punto de vista. Porque lo que ocurre es que, en este ejemplo, aunque el mecanismo de la empatía parece que no está actuando en el bebé sino en la madre, el hecho es que la empatía ya está actuando ahí de algún modo y ya está envolviendo su vida desde el primer día de su nacimiento, ya sea porque a él llega proveniente de la madre o de cualquier otro congénere que esté con él. Y, de todos modos, con otro ejemplo veréis que sí está funcionando la empatía en el bebé, incluso en sus dos primeros meses de vida. Todos sabemos que para un recién nacido el recibir afecto es tan vital como el recibir alimento. ¿Cómo le hace llegar la madre a su recién nacido el afecto? ¿Usa las palabras de su lengua cultural para darle toda una explicación de que él es un bebé querido porque lo deseaban y les hacía mucha ilusión que naciera? No; no le va a explicar esto de esta manera, aunque quizás le guste hablar con él y, hablando, se le ocurra decirle todo este tipo de cosas. La madre le hará llegar a su recién nacido el afecto por el cuerpo y el bebé recibirá este afecto también por su cuerpo. El cuerpo de la madre coge y toca con suavidad el cuerpo de su bebé y lo aproxima al suyo, lo mece, lo aprieta contra su pecho, le da de mamar, le habla con un tono dulce y suave, le canta, lo acaricia...Y el bebé, que percibe también con su cuerpo ese calor, ese tono de voz, esas caricias, esa sonrisa de la madre (en este caso si es que tiene ya más de dos meses y ya 
puede verla), entra en intercomunicación con ella sintiendo (empáticamente) lo que la madre le está transmitiendo de ese modo tan carnal, tan corpóreo. La madre sonríe y el cuerpo del bebé todo él sonríe también. Tenemos, pues, aquí una intercomunicación y una comprensión entre ambos sin palabras y sin razonamientos. Se trata de estar uno en la experiencia pre-racional del otro, de estar ya de hecho en esa experiencia: en la experiencia de la comprensión e interpretación empática de las expresiones corporales del otro. Husserl decía que por los actos del otro, por su cuerpo, yo veo y comprendo, y ambos, el otro y yo, yo y el otro, entramos así en una especie de "unidad empática"11. Una condición apriorística hace posible esta unidad: el cuerpo del bebé es como el de la madre y el de la madre es como el del bebé. Ambos comparten una misma carne (chair $)^{12}$, como decimos en el lenguaje técnico de la fenomenología. De ahí la apercepción empatizante del otro ${ }^{13}$. ¡Compartimos un mismo cuerpo! De ahí que yo pueda "sentir con" mi bebé su sufrimiento al escuchar sus lloros y al ver su agitación y al tocar su piel y notar que está hirviendo de calor. De ahí que yo pueda percibir la alegría de mi amiga por su modo de sonreir y de moverse y alegrarme yo también. De ahí que cuando mi colega camina pesadamente y con demasiada lentitud con su cuerpo decaído yo pueda percibir que está muy triste o deprimido o que, por lo menos, algo no va bien para él. Es que la compenetración empática, natural, nos entrelaza a unos con otros, y actúa como un excelente mecanismo para expresar, comprender e interpretar de un modo inmediato y natural. A la especie le conviene esta compenetración en términos de supervivencia y de convivencia.

Todavía pondré otro ejemplo. Si un adulto entrara ahora en esta sala con un niñito de dos años porque quiere asistir a este acto y no tiene donde dejarlo, pudiera ser que al entrar aquí el niño se echara a correr y molestara con el ruido de sus zapatos sonando en el suelo y con sus grititos y risas. El adulto sabría entonces muy bien que, si intenta explicarle al niño que aquí la gente está guardando silencio y que nadie puede hacer ruidos que molesten a los demás porque ésta es una conferencia de filosofía y estamos en un acto universitario, etc., etc., lo normal es que el niño no entendiera toda esta explicación y, por

11 Cfr. Hua. XIV, Zur Phänomenologie der Intersubjektivität, vol. II, Den Haag: M. Nijhoff, 1973, p. 400; y Hua. XV, Zur Phänomenologie der Intersubjektivität, vol. III, Den Haag: M. Nijhoff, 1973, pp. 417 y 473.

12 Cfr. E. Husserl "Le monde anthropologique", en Alter 1 (1993) 274-276. Este texto corresponde a la traducción realizada por Natalie Depraz del texto n 28 del vol. XXIX de Husserliana Die Krisis der europaïschen Wissenschaften und die transzendentale Phänomenologie.

13 Cfr. Roberto Walton "Fenomenología de la empatía", Philosophica 24-25 (2001-2002) 409-428. Se trata de un excelente estudio sobre la empatía estrechamente ligado a las fuentes husserlianas. 
tanto, que siguiera en lo suyo. Pero si el adulto se ve forzado a actuar con eficacia para que el niño deje ya de correr y de gritar, puede hacerle un gesto firme con su mano y con su cuerpo para que regrese rápidamente a donde está él y puede ponerle cara de recriminación y de enfado y hacer ademán de darle unas chaparretas si vuelve a correr y a gritar. El niño no hubiera entendido sus palabras con toda su argumentación "racional" expresada en ellas, pero sí que comprende "empáticamente", y de modo inmediato, los gestos del cuerpo de ese adulto, la expresión de su rostro, el tono reprobatorio de su voz, su dedo en los labios haciéndole un fuerte ¡chis!, etc. Hay aquí una comprensión del todo natural, operada de cuerpo a cuerpo; hay aquí una expresión y comprensión interpretadora empáticas. ¿Por qué tiene el niño este mecanismo en funcionamiento? Y, ¿podría no tenerlo? Vosotros sabéis que, en los humanos, lo que no nos da la naturaleza puede proporcionárnoslo la cultura. Pues bien, la empatía es una prueba de que también tenemos la situación inversa: lo que el sujeto no puede todavía conseguir de una forma racional y cultural, va a dárselo la naturaleza biológica. Es decir, aquello que el sujeto no puede todavía conseguir por un medio racional y cultural, bien sea debido a su corta edad e incompleto desarrollo neurológico y fisiológico, bien sea debido a que necesita una respuesta rápida, instantánea, a su problema, y no podría permitirse tomarse tiempo en, por ejemplo, dialogar y argumentar para intentar que el contertulio se ponga en su situación y haga lo que se precisa en ese momento, etc., puede proporcionárselo -en el caso de la empatía- su propia naturaleza cuando ésta está trabajando al unísono con la del otro que tiene ante él. En el ejemplo que acabo de poner del adulto y del niñito en esta sala, se puede apreciar que, en casos como éste, el mecanismo de la empatía es totalmente necesario en el niño para poder él irse integrando en el núcleo familiar y en su comunidad cultural; es decir, para ir haciendo lo que los de su grupo hacen. Lo que el niño todavía no es capaz de conseguir racional y culturalmente puede, conseguirlo pre-racionalmente, captando al modo empático lo que ese adulto le pide; es decir, comprendiéndolo, interpretándolo, empáticamente. Es como si nuestra propia biología nos hubiera dotado de esta valiosísima capacidad de empatizar que, al venirnos dada de forma natural, genética, en nuestra biología de animal humano, es, por tanto, una capacidad universal, o sea, una capacidad y una posibilidad que todos nosotros poseemos; por tanto, apriorística, y la cual puede por eso mismo ponerse en marcha siempre que por lo menos dos congéneres humanos estén el uno frente al otro, y con independencia de circunstancias -que en este caso no son significativas- tales como la diferencia de edad, o de raza, o de sexo, o de cultura, etc.

No nacemos preparados para conocer las cosas como tales cosas; esto requiere un proceso de aprendizaje dentro de cada cultura concreta. Sin embargo, sí nacemos preparados para comprender al otro y, como nunca podemos 
dejar de estar en la experiencia de lo ajeno, en la experiencia de un "tú", por eso nunca dejamos estar en la experiencia de comprenderlo porque ese "tú" es esencialmente expresión corpórea natural y "yo" soy esencialmente comprensión corpórea natural. Percibir al "tú" es siempre para un "yo" interpretar, comprendiéndola, su expresión. Y ya estamos permanentemente y siempre, querámoslo o no, en esta experiencia. Decía Cassirer que esta comprensión es, incluso, esencialmente anterior al "conocimiento de las cosas". La experiencia del "tú", de un "tú"con su carácter expresivo espontáneo, tiene un modo de ser muy distinto al de mera cosa. Nosotros estamos permanentemente-decía él-en "la comprensión de la expresión"14; dicho por nosotros de otra manera, ante un "tú", es decir, en la experiencia de este texto de la corporalidad viviente que todos compartimos y por medio del cual todos y todas nos interrelacionamos, nos expresamos y nos comprendemos de modo inmediato. Y -como indica Roberto Walton- al igual que en el idioma propio no percibimos las palabras sólo como un sonido físico sino ya con su sentido, esto mismo ocurre con el cuerpo del otro. Mi comprensión del otro no es un anexo de la percepción de su cuerpo físico. Porque, realmente, nunca estamos ante un cuerpo físico, sino ante una corporalidad viviente, esto es, ante una corporalidad expresándose para otra corporalidad ${ }^{15}$.

\section{II}

$\mathrm{Y}$ bien, ¿quiere todo esto decir que la corporalidad humana es un texto "únicamente natural"? Por supuesto que no. Esto quiere decir (a) que ser un texto natural y vivir, sin poder evitarlo, en la renovada experiencia de la expresión y de la comprensión empáticas, es lo que primordialmente somos, (b) que todos ya estamos en esta experiencia involuntaria e inesquivablemente y (c) que este texto es la cuna de todos los demás textos posibles, es decir, de los textos culturales. Y esto implica que es la cuna incluso de ése que es el texto cultural por excelencia, el primero de todos y base de todos los otros textos culturales: nuestro cuerpo humano. En efecto, no sólo la corporalidad humana es el texto natural base de todos los textos culturales posibles, sino que ella misma es "también" un texto cultural. ¡Es que no podría no serlo! Además, es el primer texto cultural existente, anterior a todos los demás textos culturales posibles y la base primordial de todos ellos, ya estén éstes en soporte papel, en

14 Cfr. Ernst Cassirer, Filosofía de las formas simbólicas, México, F.C.E., 1976, cap. II, p. 81.

15 Cfr. Roberto Walton, op. cit., p. 414. 
soporte digital, o en cualquier otro tipo de soporte artificialmente creado. $\mathrm{Al}$ ser un texto cultural, es expresión de lo que en él se tiene el propósito explícito, buscado racionalmente, de expresar. Como recordaremos, cuando al comienzo de esta exposición anuncié la tesis que aquí iba a desarrollar, dije que la expresión e interpretación de la corporalidad humana no son racional-simbólicas en su modo primigenio de darse, aunque, por supuesto que, de un modo u otro, al tener que comenzar la vida el individuo dentro de un grupo cultural, muy pronto esta expresión y esta comprensión se convertirán también -digo "también" y no sólo- en culturales, es decir, en simbólicas, con intervención de nuestro raciocinio y siguiendo un propósito racional. Veamos, pues, esto, aunque no podremos extendernos mucho.

La primera cuestión que se nos plantea es si esto que ahora estoy diciendo no entra en contradicción con todo lo que acabo de desarrollar. Porque, ¿en qué quedamos?: la corporalidad, ¿es esencialmente expresión y comprensión naturales y, consiguientemente, la empatía es el mecanismo natural biológico que nos posibilita su comprensión, o, por el contrario, la corporalidad es expresión cultural-simbólica que, como tal, ha de ser comprendida usando habilidades racionales y aprendidas? ¿Se trata de una cosa o de la otra cosa? Formulado de otro modo: la corporalidad humana, ¿es un texto natural o un texto cultural? Y, en todo caso, ¿será que comienza siendo un texto natural, dotado de comprensión empática, y que, al cabo de un tiempo, pasa a convertirse en un texto ya simplemente cultural? Pues no exactamente. Es algo un poco más complejo que esto de "o lo uno o lo otro", o primero lo uno "y después" lo otro. La corporalidad humana sufre un doble proceso de construcción cultural que se inicia desde que nace el individuo. Y, aunque el resultado, por partida doble, es que nuestra corporalidad es prácticamente desde el principio un "texto cultural", es éste es un proceso enteramente "natural". Es decir, que en ningún caso podría no darse este proceso. Es como si ya estuviera programado biológicamente en todos nosotros que nuestra corporalidad sea, desde el principio, también un texto cultural.

En primer lugar, como sabéis, una de las características más definitorias de los humanos es que somos, a la vez, naturaleza y cultura. No somos seres naturales del todo ni tampoco somos del todo seres culturales. Si la cultura no le proporciona ayuda, entonces la supervivencia del sujeto, como individuo y como grupo, se haría muy difícil y hasta imposible. ¡Necesitamos la ayuda de la razón y de nuestra cultura -la que sea- para mantener con éxito nuestras vidas! A diferencia de lo que ocurre en el resto de los animales, nuestra biología no trae consigo, en su genotipo, estos rasgos que nos caracterizan como especie humana; tan sólo trae la capacidad para hacernos con estos rasgos. Como antes decíamos, nuestros rasgos básicos como especie humana sólo podemos adquirirlos como consecuencia y como resultado final de todo un proceso de aprendizaje: si caminamos bípedamente, si tenemos un lenguaje simbólico, si 
razonamos simbólicamente y si somos capaces de transformar sofisticadamente la naturaleza con nuestras manos, todo esto es fruto de un aprendizaje que nos viene de nuestros congéneres. Y no es que para llegar a hacerse humano y ser reconocido un miembro de nuestra especie con estos que son nuestros rasgos básicos, la nueva criatura únicamente necesite tiempo hasta que vayan aflorando en ella estos rasgos de modo espontáneo o natural. No es así como esto sucede. Sería imposible. Ellos han de ser, necesariamente, el resultado de un proceso de aprendizaje que tiene como elemento mediador el cuerpo, tanto el de la nueva criatura como el de los congéneres que están con ella. Pensemos, por ejemplo, en el lenguaje. El bebé emite sonidos, pero esto no es lo que llamamos lenguaje humano, el cual deberá aprender. Los otros le hablan y él, poco a poco, irá comprendiendo esa lengua concreta (español, chino o irlandés...). Pues bien, desde el momento en que se le habla y se le enseña a hablar, a la nueva criatura se le va imponiendo un discurso, esto es un vocabulario y no otro y, a través de él, una cierta interpretación del mundo y de sí misma, y no otra. Porque no se trata de que la lengua o idioma de la cultura en la que nacemos nos permita a cada uno o a cada una entender la realidad de una forma "neutra", idéntica en todo el universo humano, sino de que aprender a hablar mediante un lenguaje simbólico en el marco de una cultura concreta, la que sea, supone siempre hacerlo "desde un idioma determinado", esto es, dándole un nombre a ciertos aspectos de la realidad que, por lo sean, destacan, y creando, así, los conceptos -de las cosas- dentro de la red de relaciones teórico-prácticas en la que estos van a ir enmarcados. Esto significa que a medida que la nueva criatura va asumiendo el idioma de su entorno cultural, en realidad con él se le está haciendo llegar una forma política de interpretarse a sí misma, a los otros congéneres y al resto de los elementos de su mundo. A través de la palabra (del idioma concreto de la cultura concreta en la que ha nacido y se está criando), va a pensar según piensan los otros ${ }^{16}$. Y lo mismo podríamos decir de los otros rasgos, incluso del bipedismo (a poco que nos fijemos notaremos que en la cultura japonesa, por ejemplo, la gente no desplaza su cuerpo caminando bípedamente del mismo modo como hacemos, enla cultura mediterránea). Y no trasformamos igual la naturaleza, sino que en unas culturas la trabajan de un modo y en otras de otro, usando el cuerpo de diferentes maneras para ello, manejando diferentes herramientas, etc. Por tanto, es evidente que nuestro cuerpo, texto natural, es desde el principio, también un texto cultural en cuanto que debe hacerse con los rasgos básicos propios de la especie humana. $Y$ esta es una primera construcción cultural que nuestro cuerpo sufre.

16 Cfr. M ${ }^{a}$ Luz Pintos "Cuerpo de mujer y violencia simbólica: una realidad universal”, en M a Carmen López Sáenz / Jacinto Rivera de Rosales (eds.), El cuerpo. Perspectivas filosóficas, Madrid, UNED, 2002, pp. 291-315. 
Pasemos ahora a la segunda construcción cultural que sufrimos. Y es que sólo teniendo en cuenta ambas nos daremos cuenta de que, a pesar de ser ya desde el principio un texto cultural, nunca dejamos de ser también un texto natural. Y esto es consecuencia de esta característica tan nuestra de ser, a la vez, naturaleza y cultura.

Biológicamente estamos conformados de tal modo que nuestras carencias naturales debemos superarlas con la ayuda de nuestro entorno cultural. Una de las afortunadas carencias en nuestras vidas de humanos es la falta de instintos. Nacemos con una serie de instintos que nos ayudan mucho durante los dos primeros meses de vida. Por ejemplo, cuando algo roza los labios del recién nacido éste se ve movido, instintivamente, a ponerse a succionar; cuando el recién nota un roce en su mejilla, instintivamente se vuelve con su carita y con todo él hacia ese lado (supuestamente el pecho de su madre; como todavía no puede buscarlo con la vista, tiene que haber algún procedimiento de tipo mecánico, instintivo, que le lleve a dirigir su cara y su boca hacia el pecho aunque no pueda verlo), etc. Estos y otros instintos semejantes tienen la función de ayudar a la nueva criatura mientras ésta no pueda valerse por otros medios. A los dos meses, con más madurez neuronal y psicomotriz, no necesitará ya de estos instintos y estos desaparecen prácticamente todos (sólo se mantiene el instinto de apnea pero tan sólo por unos cuatro meses más). Y en lo que le resta de vida ya no tendrá ningún instinto o éstos tendrán un carácter muy débil ${ }^{17}$. No necesita de los instintos porque puede suplirlos con las nuevas posibilidades psicomotrices que ahora sí posee y, desde luego, con la inteligencia racional, la cual siempre estará ya culturalizada. De ahí que, una vez más, podamos declarar: lo que la naturaleza no da-o, en el caso de los instintos, lo que ya no da más allá de esos primeros meses de vida-, la cultura lo proporciona. Y, en caso de no ser así, peligraría nuestra supervivencia.

Al no nacer predeterminados instintivamente, y al nacer sin hacer y ser, pues, plásticos y abiertos a infinitas posibilidades según lo que la cultura en que hemos nacido haga de nosotros, el resultado es que cada sujeto humano

17 Que los instintos del sujeto estén muy debilitados supone que fácilmente la cultura podrá interferir en ellos para anularlos o desviarlos de su finalidad natural. Es el caso, por ejemplo, del llamado "instinto de sobrevivencia", o del llamado "instinto materno". Como en la cultura occidental se cultiva el valor del "aparentar" ante los demás este valor puede tener predominio sobre la búsqueda de la propia sobrevivencia y favorecer en un joven el querer lanzarse en moto por una carretera infernal a una altísima velocidad aun sabiendo él que es más que probable que muera en el intento. En India o en China, la preferencia cultural por un primogénito varón hace que las propias madres abandonen o maten a sus hijas recién nacidas. Por tanto, en ambos casos, una interferencia cultural de tal calibre en lo que en principio es una conducta instintiva únicamente se explica por el debilitamiento de la carga instintiva en el ser humano. 
es siempre un reflejo de lo social. Cada uno de nosotros y de nosotras, los humanos, va a sufrir desde el primer momento de su existencia una construcción social. Esto es, los otros que rodean al nuevo sujeto van a actuar sobre él en un triple sentido: en la conformación de sus creencias (sobre todas las cosas que le rodean y sobre sí mismo), en la determinación de sus emociones (que siempre son valoradoras) y en su comportamiento. Hasta tal punto ningún ser nacido de mujer se libra de esta triple construcción cultural sobre él que, como dice Husserl cuando describe esta situación -y ésta es una de las piezas clave de la fenomenología-, es cosa natural e inevitable que el nuevo sujeto tome por "natural" todas las ideas, valores y modos de comportamiento que a él llegan y le inculcan desde el primer momento y que, por el contrario, tienen carácter "cultural". La que Husserl llama "actitud natural ingenua" en el sujeto es esto de ingenuamente-tener-por-"natural"-su-mundo-"cultural". Únicamente con el paso del tiempo será posible que vaya consiguiendo "distanciarse" e ir viendo en perspectiva su cultura (esto es, hacer epojé de ella) a medida que descubra que otros modos de pensar son posibles, que otro modo de sentir emocionalmente es posible, y que otra forma de actuar es posible o, incluso, necesaria y hasta mejor. La sociedad somete a aprendizaje racional-simbólico, es decir, cultural, la esfera de nuestro pensamiento, de nuestras emociones valoradoras y de nuestro comportamiento. Por tanto, parece que nuestra corporalidad humana es, a la vez, un "texto natural" y un "texto cultural-simbólico"?

\section{III}

Veamos ahora si esto se refleja también en cuanto a la empatía. La corporalidad humana se mantiene siempre, durante toda la vida del sujeto, como un texto natural; y nunca deja de serlo (aunque no sólo va a ser un texto natural). La expresión de dolor en mi rostro seguirá aflorando siempre de un modo espontáneo cuando algo me cause gran dolor. Y tú, que me ves en mí el dolor, lo captarás como tal de un modo empático inmediato, serás capaz de sentir lo mal que me siento. Y esto sucederá ya tengamos dos añitos, treinta años o setenta años. ¿Por qué? Pues porque como mecanismo biológico de comprensión rápida, cuando vemos que el otro siente dolor, es muy útil en términos de sobrevivencia para el sujeto particular y para el grupo como tal. Puede servir para acudir a quién lo necesita, y así reforzar lazos de convivencia al ayudarse los unos a los otros. O puede servir para alejarse inmediatamente en el caso de que el dolor del otro, que uno siente en sí mismo, actúe como señal inequívoca de que hay que huir porque lo que ha pasado a él le va a pasar también a uno mismo. Y, en este segundo caso, empatizar el dolor del otro sirve para proteger la propia vida, al huir. En ambos casos, cuando un sujeto tiene dolor y éste se refleja en 
su rostro y en los gestos, movimiento y postura de su cuerpo, el otro que lo ve así capta de modo inmediato y natural su dolor en todas estas señales corpóreas. Sin embargo, aunque esta comprensión va de soi, la construcción cultural que cada sujeto sufre, se interpone interfiriendo en la reacción que, de modo natural, como una respuesta biológica, automática, puramente animal, se derivaría al ver al congénere en su expresado dolor. Y la interferencia puede, por ejemplo, ir en el sentido de interrumpir esa espontánea respuesta de ir hacia este otro que se está doliendo para ayudarlo. ¡No es que no sigamos sintiendo el dolor del otro! Sí lo sentimos, pero puede que ya no acudamos en su ayuda y que, en cambio, nos apartemos de él. ¿Por qué esto? Hemos visto muchas veces escenas como ésta: Va una madre por la calle llevando de la mano a su hijo de tres, cuatro, seis años. En una esquina hay un hombre anciano, que tiene su frente ensangrentada y pone gestos de mucho dolor. El niño lo ve y al momento (si no es tímido) siente el impulso de, por lo menos, detenerse y, acaso, de ir hacia él. Pero la madre que se percata de la situación, tira con determinación de la mano del niño para pasar de largo al mismo tiempo que le va diciendo que no se acerque a él, que puede ser un hombre malo (quizás ella esté pensando, con su buena lógica, que se trata de un drogadicto, o de un borracho, o un camorrista que se ha peleado y ahora tiene una herida), o que puede estar enfermo y contagiar algo, o que puede ser peligroso, o cualquier explicación de este tipo. ¿Cuál es, en este caso, el aprendizaje cultural del niño? Sin duda, que debe ser cauto y reprimir su impulso natural de, comprendiendo el dolor del otro, interesarse por él y acudir a su lado; impulso que, al parecer, es incorrecto, inapropiado, peligroso. Y como siga tirando de la mano de su madre ésta puede que le regañe más todavía. En adelante, su comprensión empática seguirá operando cada vez que este sujeto vea a un congénere en similar situación. Pero él ya ha aprendido a no hacer siempre caso de su sentir-con-el-otro-lo-que-el-otro-está sintiendo y a alejarse de él. O puede suceder también el caso contrario: estoy en la cola del cine para comprar una entrada. De repente, veo que aparece un loco con una navaja y se la clava en el brazo a la persona que tengo delante y que ella sangra y se retuerce de dolor. Capto empáticamente su dolor y percibo la situación como una amenaza para mí misma que también estoy ahí. Huiría inmediatamente. ¡Ah!, pero es que en mi cultura me han inculcado el principio de ayudar a quien lo necesita. Y la necesidad de esta persona herida es evidente para mí y esto me hace tomar la decisión, racional, de quedar ahí y atenderla pese al peligro $^{18}$. Por tanto, tanto en el primer ejemplo que hemos visto como en éste,

18 Nos hemos centrado en toda esta exposición en la empatía natural, pero por supuesto que, sobre la base de ésta, también puede darse en nosotros un tipo de empatía racional buscada y cultivada conscientemente por las culturas concretas. Es éste el tipo de empatía que se promueve 
entre la expresión dolorosa del otro que uno ve directamente y comprende por empatía, y la respuesta que surge de forma instantánea de esta comprensión, se puede interponer la cultura produciendo otro tipo de respuesta que, en ninguno de los ejemplos, sería natural, sino cultural.

En conclusión, hacer una fenomenología del cuerpo como expresión y comprensión e interpretación nos sitúa ante un texto que es, al mismo tiempo, "natural" y "cultural". Y esto no podría ser de otro modo. La interdependencia sujeto-mundo que en fenomenología tenemos por un a priori (el a priori de correlación universal) no ha de llevarnos únicamente a la consideración de que lo que es el ser humano como corporalidad viviente lo es por estar enclavado en un mundo de sentido simbólico-cultural concreto, sino también a la consideración inversa: el factor biológico juega un importante papel (constitutivo trascendental) en el arranque del fenómeno humano y simbólico-cultural. Nuestro cuerpo es, pues, al unísono, un texto natural y un texto cultural. De modo que no podría darse el segundo sin el primero (el simplemente "animal") y que no podría no darse el segundo y seguir siendo animales "humanos".

desde una postura ética. Se trata de procurar en el sujeto el reconocimiento de lo que al otro le está pasando para, racionalmente, ponerse en su propia situación y comprenderle. Sin embargo, mientras el mecanismo biológico de la empatía "natural" no puede no darse, el intentar racionalmente ponerse en la piel del otro puede no buscarse, ni a nivel del sujeto particular ni a nivel de alguna cultura. Y, en todo caso, el segundo tipo de empatía siempre serviría para "reforzar" el primero ya siempre presente. 
